\section{Fossilized theropod soft tissue}

SIR - I report here the discovery of a small non-avian theropod dinosaur with extremely well-preserved soft tissue, including muscle fibres, in Cretaceous rocks of Brazil. Such well-preserved soft tissue calls attention to the anatomical details that can be preserved in fossils of terrestrial vertebrates.

The specimen (MCT 1502-R; Departamento National da Producao Mineral, Rio de Janeiro) is preserved in a calcareous concretion, typical of those from the Santana Formation (Romualdo Member, Albian) of the Araripe Basin, northeastern Brazil ${ }^{1}$. This area is rich in fossils, but remains of dinosaurs are rare $^{2}$. The material comprises the pelvis, hindlimbs and some caudal vertebrae. The presence of three comparatively large pedal digits, of which the third is the largest, supports its placement in the Theropoda ${ }^{3}$. Preliminary comparisons suggest maniraptoran affinities.

Soft tissue is preserved in several parts of the nodule. It can be distinguished from the matrix and bones by the bright colours and different texture, except near the unguals, where the replaced horny covering is darker than the bone. The epidermis is very thin $(\sim 0.04 \mathrm{~mm})$, and formed mostly by irregular quadrangles bordered by deep grooves, presenting a criss-cross pattern. No evidence was found of any structure covering the skin, such as dermal ossicles, scales or feathers, which should be preserved if they were originally present.

A sample of the soft tissue in the femur-tibia-fibula area was removed and analysed by scanning electron microscope (SEM). On the dorsal view, fibrous structures could be identified. They are polygonal in transverse section and in the area examined their diameters range from 30 to $50 \mu \mathrm{m}$. A carbon-coated section was submitted to energy dispersive spectroscopy for elemental characterization, which showed that those structures are preserved as calcium phosphate. They represent striated muscle fibres, some of which even show partial striations ( $a$ and $b$ in the figure). Phosphatized soft tissue from the Santana Formation were previously reported in fossil fishes ${ }^{4}$ and pterosaurs $^{5-7}$. It has also been replicated in laboratory experiments ${ }^{8}$.

Longitudinal and cross-sections of a femur fragment were also examined by SEM. The transverse section of this bone shows channels for blood vessels (diameter 20-25 $\mu \mathrm{m}$ ) and lacunae for osteocytes (diameter $\sim 5 \mu \mathrm{m}$ ). Rod-like structures have been preserved in some channels ( $c$ in the figure). Some show a
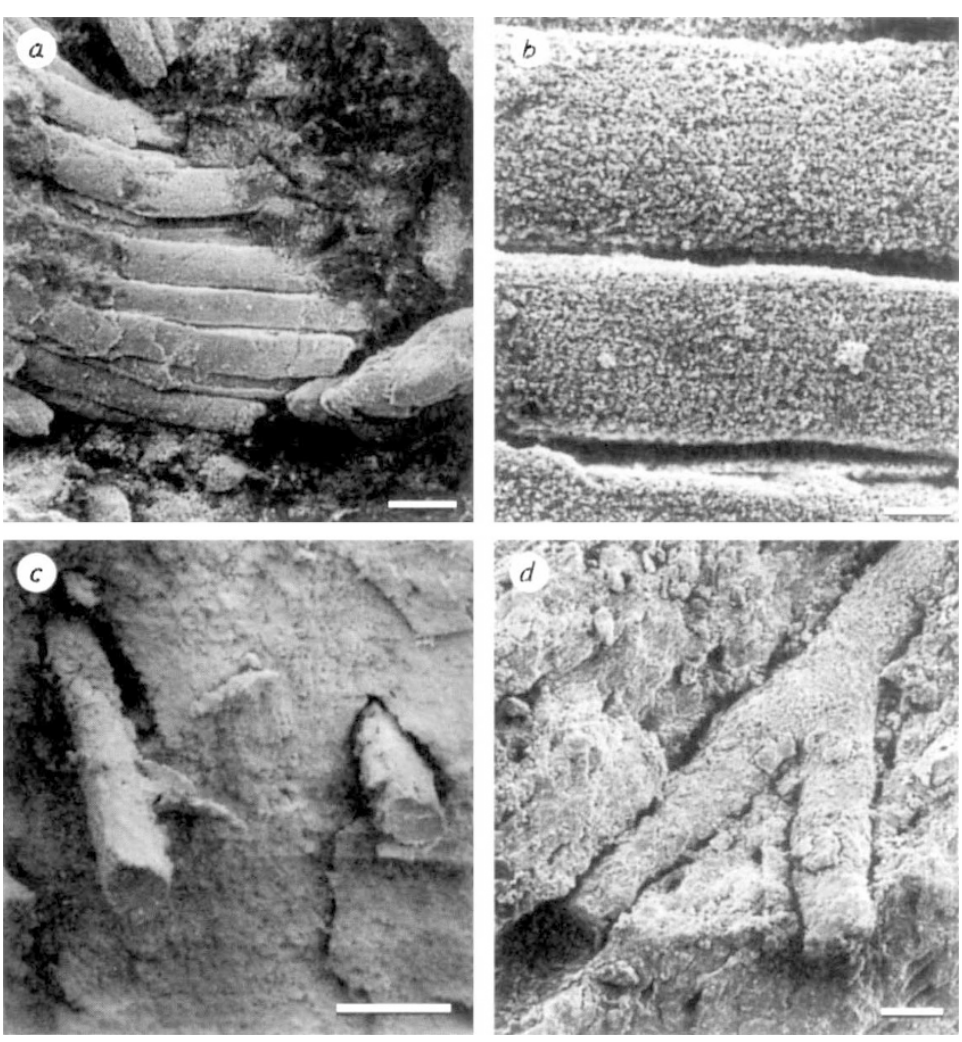

Scanning electron micrographs of samples from an Early Cretaceous theropod dinosaur. a, Severa muscle fibres, and $b$, detail of muscle fibres from a soft tissue sample (note the striations indicated by darker lines transverse to the fibres). $c$, Detail of the transverse section showing two rod-like structures coming out from the channels for blood vessels; $d$, detail of the longitudinal section, showing a branching structure preserved in the blood channels of a femur. The sample was etched in a $3 \%$ formic acid solution saturated with calcium phosphate for $5 \mathrm{~min}$, and neutralized in plain water. After natural drying, it was mounted on carbon-based tape, further coated with a goldpalladium layer, and analysed by SEM (Zeiss DSM 950; American Museum of Natural History). Scale bars: $a, 50 \mu \mathrm{m} ; b, 10 \mu \mathrm{m} ; c, 20 \mu \mathrm{m} ; d, 20 \mu \mathrm{m}$.

different texture from the matrix and bone: the inner portion is smooth and covered by a rougher outer layer. Longitudinal sections show these structures branching off to nearby channels ( $d$ in the figure). The outer layer of those structures is rich in calcium phosphate, although not as rich as the bone. Both differ from the calcium carbonate matrix.

These structures can be interpreted as mineralizations filling the channels for capillary blood vessels of the bone, or they might represent the replacement of the blood vessels themselves. The fact that some of these structures have a smaller diameter than the channels in which they are preserved prevents the exclusion of the second hypothesis.

Most dinosaur soft tissue reported is preserved as impressions (for example, refs 9-11), and in one case as a kerogenous film of the skin ${ }^{12}$. None approaches the condition of the material examined here, where not only the skin but also muscle fibres and other soft tissues are preserved in three dimensions. Careful collecting and preparation of other dinosaur specimens can provide more such material and might contribute to a better understanding of the biology of these extinct animals.

Alexander W. A. Kellner

Fellow CNPq, Brasilia, and Department of Vertebrate Paleontology,

American Museum of Natural History, New York 10024-5192, USA

1. Maisey, J. G. (ed.) Santana Fossils, An illustrated Atlas (TFH, New Jersey, 1991).

2. Campos, D. A. \& Keliner, A. W. A. in Santana Fossils, An Illustrated Atlas 372-375 (TFH, New Jersey, 1991).

. Gauthier, J. Mem. Calif. Acad. Sci. 8, 1-55 (1986).

4. Martill, D. M. Palaeontology 31, 1-18 (1988).

5. Martill, D. M. \& Unwin, D. M. Nature 340, 138-140 (1989).

6. Kellner, A. W. A. Anuar. Inst. Geoci. 1989, 86-106 (1990).

7. Kellner, A. W. A. Acta geol. leopold. 39, 615-625 (1994).

8. Briggs, D. E. G. et al. J. geol. Soc. Lond. 150 1035-1038 (1993).

9. Osborn, H. F. Mem. Am. Mus. nat. Hist. 1, 31-54 (1912).

10. Bonaparte, J. F. \& Powell, J. E. Mém. Soc. géol. Fr. 139, 19-28 (1980).

1. Bonaparte, J. F. et al. Contr. Sci. 416, 1-42 (1990).

12. Martill, D. M. Mod. Geol. 16, 61-68 (1991).

\section{Charcot's or ALS}

Cleveland et al. wish it to be known that all reference to amyotrophic lateral sclerosis (ALS) as Charcot's syndrome in the title and text of their recent Scientific Correspondence ${ }^{1}$ was inserted by the editors of Nature.

1. Cleveland, D. W. et al. Nature 378, 342-343 (1995) 